\title{
Erratum to: Toxicity assessment of silver nanoparticles in Persian sturgeon (Acipenser persicus) and starry sturgeon (Acipenser stellatus) during early life stages
}

\section{Ashkan Banan ${ }^{1}$ - Mohammad Reza Kalbassi ${ }^{1}$ - Mahmoud Bahmani ${ }^{2}$.} Mohammad Ali Yazdani Sadati ${ }^{2}$

Published online: 4 April 2016

(C) Springer-Verlag Berlin Heidelberg 2016

Erratum to: Environ Sci Pollut Res

DOI 10.1007/s11356-016-6239-7

The original version of this article unfortunately contains mistakes.

Mohammad Reza Kalbassi is the sole corresponding author. The correct names of the co-authors are shown in this article.

The online version of the original article can be found at http://dx.doi.org/ 10.1007/s11356-016-6239-7.

$\triangle$ Mohammad Reza Kalbassi kalbassi_m@modares.ac.ir

1 Fisheries Department, School of Marine Sciences, Tarbiat Modares University, P.O. Box 46424-356, Noor, Mazandaran, Iran

2 International Sturgeon Research Institute, P.O. Box 41635-3464, Rasht, Gilan, Iran 